\title{
Ethnic segregation and performance inequality in the Swedish school system: A regional perspective
}

Forthcoming in Environment and Planning A, 2010

\begin{tabular}{|c|c|c|}
\hline $\begin{array}{l}\text { Eva Andersson* } \\
\text { eva.andersson@ibf.uu.se }\end{array}$ & $\begin{array}{l}\text { John Östh } \\
\text { john.osth@kultgeog.uu.se }\end{array}$ & $\begin{array}{l}\text { Bo Malmberg } \\
\text { bo.malmberg@humangeo.su.se }\end{array}$ \\
\hline Uppsala University & Uppsala University & Stockholm University \\
\hline Institute for Housing and Urban & Department of Social and & Department of Human \\
\hline Research & Economic Geography & Geography \\
\hline SE-801 29 Gävle & SE-752 20 Uppsala & SE-106 91 Stockholm \\
\hline www.ibf.uu.se & www.kultgeog.uu.se & www.humangeo.su.se \\
\hline +46264206516 & +46184717388 & +468164853 \\
\hline
\end{tabular}




\title{
Ethnic segregation and performance inequality in the Swedish school system: A regional perspective
}

Word count 6960

\begin{abstract}
Sweden is today an immigrant country with more than $14 \%$ foreign born. An increasing share of the immigrants comes from non-European countries. This implies that Sweden has been transformed from an ethnically homogenous country into a country with a large visible minority. In this paper we survey the effect of this change on school segregation. Building on Schelling's model for residential segregation, we argue that establishment of a visible minority has triggered a process of school segregation that in some respects can be compared to the developments in the United States. In order to test the validity of a Schelling-type process in Swedish schools we compare segregation levels in regions with different shares of visible minority students. We use data from the PISA 2003 survey in combination with register data on the ethnic composition of student population in different pats of Sweden. We find that school segregation is higher in regions with a large visible minority population. We also find that, controlling for student background, there are smaller differences in performance across schools in regions with low shares of minority students.
\end{abstract}

Key words: school segregation, Sweden, PISA, student performance 


\section{Ethnic segregation and performance inequality in the Swedish school system: A regional perspective}

Large-scale immigration is a relatively recent phenomenon in Sweden. In 1960, only 4 percent of the Swedish population was foreign-born. In 2008, the share of foreign-born had risen to 13.8 percent, 2 percentage points above the corresponding figure for the United States. The increase in the share of foreign-born has gone hand in hand with a shift in the composition of the immigrant population. Up to the 1960 s, fewer than $10 \%$ of immigrants came from non-European countries. Today, $48 \%$ of the foreign-born population is from non-European countries, with Western Asia the most important sending region. In this study we examine the effects of this change on the Swedish school system.

During the post-war period, Swedish school reforms were aimed at abolishing the old school system, which was based on an early sorting of pupils. The new comprehensive school system was named enhetsskolan (later changed to grundskolan = basic school). Enhetsskolan means 'unity school' and is a testimony to the new ideals behind the reforms. The comprehensive school system was tested for a trial period in several Swedish regions from 1949 and onwards and then became the dominant compulsory school system during the earlier parts of the 1960s. By 1972, the comprehensive school system had been introduced in all Swedish compulsory schools. Twenty years later a new chapter in Swedish school history was written: beginning in 1992, voucher schools were allowed to compete with public schools for pupils. In the beginning only a handful of voucher schools existed but according to the Swedish organisation of voucher schools, no fewer than 635 compulsory voucher schools were active in the year of 2007/2008, teaching approximately 9\% of Swedish pupils (Friskolornas Riksförbund, 2009). 
Public schools, especially the upper secondary school, have begun to react to the increasing competition from voucher schools by profiling their education. As a result, from having few or no alternatives of school profiles to choose between in the past, today's pupil may choose from many different school profiles. Consequently, an increasing number of pupils opt out of their neighbourhood schools, especially in larger urban areas where the alternatives are many (By, 2005; Oríaa et al., 2007). However, a limitation in this paper is that we are not concerned with the actual choices made; rather we consider the regional pattern and search for plausible causes for difference in pupil performance between schools.

According to the PISA 2003 report on immigrants, Sweden has a well established system for language support which appears to lessen the gap for second-generation immigrant pupils compared to first-generation (OECD, 2006). Nevertheless, the report states that this is not enough to bridge the gap with native children. Results from education in mathematics are a particular worry, as more than $40 \%$ of first-generation pupils in Sweden (as well as Belgium, France, and Norway) fail to reach level 2, which is the baseline level. Pupils below level 2 are expected to face considerable challenges in terms of labour market and earnings prospects (OECD, 2006). Sweden and Belgium have a performance disadvantage of more than 90 score points in the PISA test for first-generation pupils. The difference in results is not explained by socio-economic background, including parents' education, or by motivation to learn or attitude towards school (OECD, 2006). This means there are unanswered questions in the matter of inequality by ethnic background in Swedish schools.

In this paper, we will argue that an increasing presence of visible minorities in Sweden has been an important factor behind increasing between-school variation in student performance. Our 
argument will be based on analysis of how regional differences in school segregation and performance are linked to inter-urban differences in the share of visible minorities. According to the Schelling model of segregation, parents preferring schools with mainly majority pupils are under little pressure to opt out of neighbourhood schools or move to majority-dominated neighbourhoods as long as the presence of ethnic minorities is at a low level. When the urbanlevel share of ethnic minorities increases, pressure on parents who prefer majority-dominated schools will become stronger. And if parents make a choice based on their perception of schools dominated by minorities, this will start a process of segregation that is also likely to increase differences in performance across schools. Even if the Schelling model describes a process that develops over time it can be used also to predict cross-sectional differences in segregation. Processes of segregation are more likely to be triggered in regions with high shares of visible minorities than in regions with low visible-minority shares.

In our analysis, we will look both at inter-regional differences in ethnic and socio-economic segregation, and on the effects of segregation on performance. It can be argued that school segregation becomes a more acute problem when it affects the chances of different students to get good school results. It is, therefore, important to analyse if regions with high shares of visible minorities also have higher levels of between-school variance in student performance.

Our paper is organized as follows: in section 2 we review earlier studies of ethnic residential and ethnic school segregation. Section 3 presents our data and the design of our empirical study. Results are presented in Section 4, followed by a discussion and conclusion section. 


\section{Earlier research}

In spite of ethnic school segregation being a widely discussed issue in contemporary society, there is comparatively little research in Sweden. There has been a growing interest during the last decade (e.g Szulkin and Jonsson, 2007) but the number of publications in scientific journals remains low (Brännström 2008, Bunar 2010). This is in contrast to neighbouring Norway and Denmark (Rangvid 2007, Fekjaer and Birkelund 2007) as well as other European countries such as Germany, the Netherlands and United Kingdom (Noreich 2007, Sykes 2009, Karsten et al. 2003, Burgess et al. 2005). In Sweden, the focus has, instead, been on residential segregation (Andersson R. et al 2007, Biterman 2006, Bråmå 2008, Hedlund 2009, Murdie and Borgegard 1998, Vogel 1992).

Given that the increase in visible minority shares in the Swedish population is a relatively recent phenomenon, and given that Swedish research on school segregation is in an early phase, it is an open question to what extent lessons from the US will be of relevance for an understanding of the Swedish case. Certainly, there are big institutional differences between Sweden and the US (Friedrichs, Galster and Musterd, 2003, Galster 2002). But some researchers argue that these differences may, in fact, be the result of differences in ethnic homogeneity (Eger, 2009). Moreover, Rangvid (2007) shows that school segregation patterns in Denmark in many ways are similar to segregation patterns found in the US.

In this paper, we will not address this issue. Instead, we will concentrate on one influential hypothesis concerning the dynamics of ethnic segregation. This is the idea developed by Thomas Schelling that residential segregation can result from relatively mild preferences among the majority group for being close to people of their own kind (1978). Schelling's argument can be 
illustrated by the following example. Assume that everyone in the majority population can accept $4 \%$ minority representation in their neighbourhood. $75 \%$ can accept an $8 \%$ minority population, $50 \%$ can accept a $16 \%$ minority population, but only $25 \%$ can accept a $32 \%$ minority population. If every neighbourhood has less than $4 \%$ minorities the whites will not choose neighbourhoods based on ethnic concerns. If, however, migration leads to an increase in the minority share in a neighbourhood to $8 \%$, then $25 \%$ of the majority population will choose to leave the neighbourhood. If the vacancies created by this outmigration are filled with minority households, the minority share will increase to almost $33 \%$. This will lead to further outmigration of the majority population since only $25 \%$ of the majority population accepts living in a neighbourhood with $33 \%$ minority shares. Thus, in the end a small increase in the minority share of a neighbourhood can generate a dynamic process that leads to almost complete segregation. A more complete argument can be found in Clark (1991).

Schelling's idea has been tested by different researchers including Clark (1991) and Card (2008). Recently, Platt-Boustan (2010) has, using a Schelling-type framework, argued that the post-war movement of whites from inner cities to the suburbs was partly the result of black migration into metropolitan areas. There are also studies that confirm the importance of preferences (Ihlanfeldt and Scafidi, 2004). Studies that focus on the existence of tipping-points and threshold also include Galster, Quercia and Cortes (2000), Ledwith and Clark (2007), Li (2009) and Van Ham and Feijten (2008). In the Swedish context, Bråmå (2006) have explored white flight from immigrant dominated neighbourhoods.

Although these studies focus on processes of residential segregation we would, like Card (2008), 
argue that the Schelling framework is valid also for school segregation when parents are able to choose between schools (see also Burgess, McConnell, Propper and Wilson, 2005; Noreisch, 2007; Saporito and Lareau, 1999) Thus, the above example could be translated into a school context: Everyone in the majority population accepts a $4 \%$ minority share in the school. But if the minority share increases, a cumulative process may result in completely segregated schools. An early study of school segregation in the United States is Clotfelter (1976), but his study does not focus so much on what forces are driving segregation.

In the school segregation literature much focus has been on the patterns of segregation as well as on driving forces. But studies that focus on how segregation effects school outcomes also play an important role. These include the European studies mentioned above, Sykes and Kuyper (2009), Kauppinen (2008), Fekjaer and Birkelund (2007) Bernelius (2006), Andersson and Subramanian (2006), as well as a number of American studies.

All these studies use multilevel modelling in order to isolate the effects of school-level factors on student outcomes. Multilevel modelling is also used for the same purpose in the PISA studies. A key parameter in multi-level models is the estimated between-school variance in student performance. When individual-level factors are controlled for, the remaining between-school variance can be seen as a measure of school-level effects. These, in turn, can be related to school-level covariates such as average socio-economic status or minority share in school. Recognising that school effects can be both compositional and based on unmeasured selection effects (Dumay and Dupriez 2008; Harker and Tymms 2004) we will, in this paper, also use between-school variance as a key indicator. Our purpose is not, however, to survey the effects of 
covariates. Instead, high levels of between-school variance will be seen as indicating that a school system is characterized by large performance gaps that affect student outcomes. To the extent that these performance gaps are related to differences in the student composition of schools, between-school variance in student performance can be seen as a complementary measure of segregation.

\section{Research design and data}

To test the Schelling hypothesis we will take advantage of regional level variation in the share of visible minority school children (VMS). We use the concept of visible minority derived from the Swedish discussion, from among others the National Board of Health and Welfare (2006). Our definition is based on individuals immigrating from countries with a majority non-Caucasian population, that is, visible in the Swedish context (immigrants from Africa, Asia, the Middle East and South America). The reason for such a definition is that it focuses on the majority population's norms and values and its ability to welcome visible minorities. Hereby the interest is moved to the native Swedish population's perception and manners towards immigrant groups as an important explanation behind discrimination and integration difficulties on e.g. the labour market (National Board of Health and Welfare, 2006). In order to operationalise this measure we used fathers' country of birth. Thus, children with fathers from Africa, Asia, the Middle East and South America are classified as belonging to a visible minority (Swedish population registers do not contain information on ethnicity). Data on fathers' country of birth for all 15 -year-olds in Sweden in 2003 have been collected from the PLACE database (PLACE, Population, Chorology and Employment Database, register data from Statistics Sweden). 
The highest share of visible minority school children is found in the metropolitan areas of Stockholm, Gothenburg and Malmo. In addition there is a fairly densely populated area around two lakes, Mälaren and Hjälmaren, in mid-south-eastern Sweden that has high shares of visible minority school children. The regions in the northern parts tend to have low VMS.

If Schelling is correct, we would expect school differentiation to be more pronounced in regions where the share of visible minority school children is high. The data we used to assess the level of school differentiation was taken from PISA 2003. PISA, the Programme for International Student Assessment, is an international standard that was developed jointly by participating countries and administered in order to assess 15 -year-olds in school. The first assessment was in 2000, the second in 2003 and there was another in 2006 (OECD, 2008). For every assessment there is an increasing number of participating countries, chiefly industrialised countries. In 2003, 41 countries were included in the PISA study. In Sweden 4624 pupils in 185 schools were assessed, Table 1. The mean size of schools in the Swedish sample was 515 pupils. Schools in each country are randomly selected by the international contractor for participation in PISA. The selection of schools and students is kept as inclusive as possible, so that the sample of students comes from a broad range of backgrounds and abilities. It is also possible to compare student performance across the surveys, as well as some of the background questionnaire items.

Student and school level PISA data are available at the PISA web site, but these data do not include information about where in Sweden the schools are located. The locations of the schools have instead been determined based on information on the identity of the schools provided by the Swedish co-ordinator of the PISA study. 
In the published reports on the PISA study, multi-level statistical methods are used to assess how variation in student performance is linked to the individual level and school-level factor. In this paper, we will proceed in a similar way. Student performance will be measured by the aggregate sum of the four PISA test scores for reading, mathematics, problem solving and science. The multi-level approach allows the variation in test scores to be decomposed into the pupil level and school-level variation (for measurement limitations see e.g. Harker and Tymms (2004)). It should also be remembered that PISA is a sample survey and therefore subject to sampling variation.

If school differentiation is independent of the share of visible minority children in the region, then the estimated between-school variance should be the same in all regions irrespective of minority share. If, on the other hand, the Schelling hypothesis is correct, then we should expect higher between-school variance in regions with high shares of visible minority children.

Between-school variance in pupil performance may be the result of both individual background factors and school-level effects. To control for the influence of pupil background we will therefore also estimate a model that includes the socio-economic status of each pupil as an explanatory variable. The variable we use is the 'socio-economic and cultural index' (ESCS) of the PISA 2003 study. The ESCS variable proxies for each pupil's parents socio-economic and cultural status, and is derived from three variables measuring parents' length of education, status of employment and home possessions relating to an intellectual milieu. If this variable fails to eliminate between-school variance in pupil performance, this indicates that there are other school-level factors that influence performance. 
A possible explanation for such remaining school-level effects could be differences linked to the average socio-economic status of the pupils. It is possible, for example, that there are peer group effects on pupil motivation or that teacher quality varies between high-status and low-status schools (Ainsworth 2002; Wilson 1987). By including a school-level average for the socioeconomic and cultural index we can test the extent to which regional differences in socioeconomic school segregation determine differences in between-school variation in pupil performance.

An alternative explanation for school-level effects is that they are linked not to socio-economic but to ethnic composition. To test this idea we have calculated the average share of foreign-born pupils per school and included this variable in the estimations. The data come from the abovementioned Swedish PLACE database.

In the final step, we also consider a model where the impact of school-level socio-economic differences is allowed to vary between regions. The purpose of this estimation is to test for the possibility that quality differences between schools are more strongly linked to socio-economic factors in regions with high shares of visible minority children. If this is the case it would indicate that a racialisation of socio-economic differences has negative effects on school-system performance. The variables used in the paper are listed in table 1. 
Table 1. Variables and descriptives at different levels in analyses of Swedish data, both PISA and PLACE data

\begin{tabular}{|c|c|c|c|c|c|c|}
\hline $\begin{array}{l}\text { Level of } \\
\text { analysis }\end{array}$ & Variable & Description & Max & Min & Mean & StD \\
\hline \multirow[t]{3}{*}{ 1. Individual } & *Student ID & $\begin{array}{l}\text { Count, } 4567 \\
\text { students }\end{array}$ & & & & \\
\hline & ${ }^{*} \mathrm{ESCS} 1$ & $\begin{array}{l}\text { Socio-economic } \\
\text { and cultural index }\end{array}$ & -3.5 & 2.3 & 0.26 & 0.87 \\
\hline & *IMMIG & $\begin{array}{l}\text { Immigrant status. } \\
\text { Native pupil. Not } \\
\text { native pupil } \\
\text { (including second } \\
\text { generation). }\end{array}$ & $\begin{array}{l}\text { Dummy } \\
\text { variable }\end{array}$ & $\begin{array}{l}1=\text { not } \\
\text { native12 } \\
\%, \\
0=\text { native } \\
88 \%)\end{array}$ & & \\
\hline \multirow[t]{4}{*}{ 2. School } & ${ }^{*}$ School ID & Count, 185 schools & & & & \\
\hline & VMS-regions & $\begin{array}{l}\text { Visible Minority } \\
\text { Share in local } \\
\text { labour market } \\
\text { regions (LA) }\end{array}$ & $\begin{array}{l}\text { Dummy } \\
\text { variable }\end{array}$ & & & \\
\hline & *ESCS mean & $\begin{array}{l}\text { Socio-economic } \\
\text { and cultural index } \\
\text { mean in school }\end{array}$ & -0.71 & 1.58 & 0.26 & 0.33 \\
\hline & $\begin{array}{l}\text { Share foreign } \\
\text { born in school } \\
\text { neighbourhood } 2\end{array}$ & $\begin{array}{l}\text { Share of foreign } \\
\text { born in each school }\end{array}$ & 0 & 0.88 & 0.08 & 0.12 \\
\hline $\begin{array}{l}\text { Dependent } \\
\text { variable }\end{array}$ & $\begin{array}{l}{ }^{*} \text { PISA test } \\
\text { score, } \\
\text { aggregate }\end{array}$ & $\begin{array}{l}\text { The sum of the four } \\
\text { PISA test scores } \\
\text { (reading, } \\
\text { mathematics, } \\
\text { problem-solving } \\
\text { and science) }\end{array}$ & 413.6 & 3035.8 & 2033.6 & 342.7 \\
\hline
\end{tabular}

\section{*PISA data}

1. The socio-economic and cultural index is composed of several variables in the PISA-tests. Parents' occupation and education as well as information about their home possessions (index of cultural and educational resources at home).

2. The neighbourhood area in this variable equals SAMS (small area market statistics) constructed by the Swedish municipalities (administered by Statistics Sweden) to include homogeneous areas when it comes to tenure forms, housing types and residents. There are about 9200 areas in Sweden and they are smaller in dense urban areas and bigger in rural areas and consists of on average 1000 inhabitants.

In the analysis below, the 87 local labour market areas in Sweden were categorized into 4 types according to their share of visible minority children. The numbers of PISA schools and numbers of PISA students in these regions are given in table 2. 
Table 2. Four classes of visible minority share with number of labour market regions and pupils (PLACE database).

\begin{tabular}{|l|r|r|r|r|}
\hline & \multicolumn{5}{|l|}{ Four types of regions } \\
\hline Visible minority share & No. regions & No. pupils & No. Schools & Share of visible minority children, \% \\
\hline VMS low & 45 & 677 & 26 & $0.0-2.5$ \\
\hline VMS medium & 23 & 1133 & 45 & $2.5-5.0$ \\
\hline VMS medium/high & 14 & 645 & 26 & $5.0-10.0$ \\
\hline VMS high & 5 & 2112 & 87 & $10.0-25.0$ \\
\hline Total & 87 & 4567 & 184 & \\
\hline
\end{tabular}

\section{Results}

In Table 3, we present data on the level of socio-economic and ethnic segregation in the four different region types indentified above. Our measure of segregation is the intra-class correlation of the socio-economic and cultural index (ESCS) and of ethnic origin (foreign born / not foreign born). Both variables are from PISA 2003. The arguments for using intra-class correlation as a measure of segregation are similar to those advanced for using eta squared, (see White, 1986 and Massey and Denton, 1988). We obtain this measure by estimating an empty multilevel model that allows for different between school variation across regions. As can be seen in Table 3 , segregation levels, as measured by the ICC, differ substantially between regions. The results support the idea that a Schelling type process can be at work. For both socio-economic segregation and ethnic segregation, the highest levels are found in the regions with the highest share of visible minorities. 
Table 3. Socioeconomic and ethnic segregation in Swedish schools, by type of region.

\begin{tabular}{lrr} 
Region & ICC, ESCS & ICC, foreign born \\
\hline VMS low & 0.13 & 0.04 \\
VMS medium & 0.19 & 0.09 \\
VMS medium/high & 0.15 & 0.16 \\
VMS high & 0.53 & 0.72 \\
\hline
\end{tabular}

We now turn to the question of whether there are also regional differences in the extent to which student performance varies between schools. According to PISA 2003, the overall betweenschool variance in Sweden is relatively low. It accounts for $10 \%$ of the variation in student performance. Here the question is if this variation in student performance differs between Swedish regions. As shown in model 1 in table 4, which presents the results of estimating multilevel model using the MLwiN software, the answer is yes. In the model we estimate different intercepts for each region. We also allow for different between-school variance for the different regions. There are substantial differences in between-school variance across regions with different shares of visible minority school children. The highest between-school variation is found in regions with the highest shares of visible minority children. In the VMS-high regions, as much as $17.6 \%$ of the variability is associated with the school-level. In the second highest category, the VMS-medium/high region, the variability at the school level is lower, at $7.5 \%$. In the third category, the VMS-medium region, the between-school variability is small, at only $0.5 \%$. This means that the difference in result of attending one or another school is negligible for a pupil in this type of region. The VMS-low region however displays higher between-school variability $(4.6 \%)$. 
Table 4. Multilevel models with regions, pupil level ESCS and immigrant status.

\begin{tabular}{|c|c|c|c|}
\hline Parameter & $\begin{array}{l}\text { Model } 1 \\
\text { Estimate (S.E.), Sign. }\end{array}$ & $\begin{array}{l}\text { Model } 2 \\
\text { Estimate (S.E.), Sign. }\end{array}$ & $\begin{array}{l}\text { Model } 3 \\
\text { Estimate (S.E.), Sign. }\end{array}$ \\
\hline \multicolumn{4}{|l|}{ Fixed effect intercepts } \\
\hline VMS-low & $2045.882(18.243) * *$ & $2019.485(14.887)^{* *}$ & $2028.193(15.096) * *$ \\
\hline VMS-medium & $2038.964(10.303) * *$ & $2007.107(9.449) * *$ & $2020.101(9.842) * *$ \\
\hline VMS-medium/high & $2037.219(20.750) * *$ & $2010.164(18.936) * *$ & $2022.878(18.235) * *$ \\
\hline VMS-high & $2034.491(17.991) * *$ & $1980.241(13.384) * *$ & $2014.170(12.310) * *$ \\
\hline \multicolumn{4}{|l|}{ Level 1 (Pupil specific) } \\
\hline \multicolumn{4}{|l|}{ Fixed variance components } \\
\hline ESCS & & $156.326(5.278)^{* *}$ & $145.298(5.363) * *$ \\
\hline Immigrant status & & & $-151.627(15.048)^{* *}$ \\
\hline Random variance components & $\begin{array}{l}\text { Estimate, Sign.(S.E.) } \\
\% \text { of variation }\end{array}$ & $\begin{array}{l}\text { Estimate, Sign.(S.E.) } \\
\% \text { of variation }\end{array}$ & $\begin{array}{l}\text { Estimate, Sign.(S.E.) } \\
\% \text { of variation }\end{array}$ \\
\hline $\begin{array}{l}\text { VMS-low } \\
\text { (Within school) }\end{array}$ & $\begin{array}{l}99052.2 * * \\
(5488.542) 95.43 \%\end{array}$ & $\begin{array}{l}83531.47 * * \\
(4628.161) 97.13 \%\end{array}$ & $\begin{array}{l}83540.656 * * \\
(4628.796) 96.97 \%\end{array}$ \\
\hline $\begin{array}{l}\text { VMS-low } \\
\text { (Between school) }\end{array}$ & $\begin{array}{l}4740.778 * \\
(2390.741) 4.57 \%\end{array}$ & $\begin{array}{l}2470.698 \\
(1586.697) 2.87 \%\end{array}$ & $\begin{array}{l}2610.952 \\
(1626.308) 3.03 \%\end{array}$ \\
\hline $\begin{array}{l}\text { VMS-medium } \\
\text { (Within school) }\end{array}$ & $\begin{array}{l}106648.7 * * \\
(4567.257) 99.52 \%\end{array}$ & $\begin{array}{l}92186.04 * * \\
(3947.724) 99.69 \%\end{array}$ & $\begin{array}{l}90365.891 * * \\
(3869.897) 99.33 \%\end{array}$ \\
\hline $\begin{array}{l}\text { VMS-medium } \\
\text { (Between school) }\end{array}$ & $\begin{array}{l}509.771 \\
(992.679) 0.48 \%\end{array}$ & $\begin{array}{l}286.795 \\
(825.361) 0.31 \%\end{array}$ & $\begin{array}{l}606.014 \\
(879.713) 0.67 \%\end{array}$ \\
\hline $\begin{array}{l}\text { VMS-medium/high } \\
\text { (Within school) }\end{array}$ & $\begin{array}{l}89639.54 * * \\
(5092.207) 92.50 \%\end{array}$ & $\begin{array}{l}78901.2 * * \\
(4482.178) 93.08 \%\end{array}$ & $\begin{array}{l}80693.195 * * \\
(4584.136) 94.06 \%\end{array}$ \\
\hline $\begin{array}{l}\text { VMS-medium/high } \\
\text { (Between school) }\end{array}$ & $\begin{array}{l}7271.583 * * \\
(3066.293) 7.50 \%\end{array}$ & $\begin{array}{l}5864.779 * \\
(2546.389) 6.92 \%\end{array}$ & $\begin{array}{l}5094.360 * \\
(2345.175) 5.94 \%\end{array}$ \\
\hline $\begin{array}{l}\text { VMS-high } \\
\text { (Within school) }\end{array}$ & $\begin{array}{l}107992.8 * * \\
(3392.971) 82.42 \%\end{array}$ & $\begin{array}{l}90092.77 * * \\
(2830.126) 88.98 \%\end{array}$ & $\begin{array}{l}87073.633 * * \\
(2735.018) 91.64 \%\end{array}$ \\
\hline $\begin{array}{l}\text { VMS-high } \\
\text { (Between school) }\end{array}$ & $\begin{array}{l}23035.64 * * \\
(4243.855) 17.58 \%\end{array}$ & $\begin{array}{l}11157.68 * * \\
(2295.768) 11.02 \%\end{array}$ & $\begin{array}{l}7939.308 * * \\
(1776.282) 8.36 \%\end{array}$ \\
\hline$-2 * \log$ likelihood & 65907.23 (4567 cases) & 65115.70 (4567 cases) & 65018.68 (4567 cases) \\
\hline
\end{tabular}

Is the variability across schools due to differences in performance that are linked to the socioeconomic background of the pupils? To test this we include the ESCS variable (socio-economic and cultural status from the PISA assessment) in the multi-level analysis. The result is presented in model 2 in table 4. The introduction of the ESCS variable at the individual level lowers the between-school variability in all regions. As was expected, socio-economic and cultural status partly explains differences in achievements in the PISA tests. However, the regional differences 
observed in the previous model persist. Similar results have been reported in a paper from Statistics Sweden (SCB, 2007), in which several variables were controlled for, including parental education, family composition, ethnic background, time in Sweden and type of housing, but regional differences persisted. In model 3, table 4 immigrant status is introduced. Controlling for immigrant status implies lower between-school variation. Still, however, the differences across regions remain. This implies that the pattern described in model 2 is not due only to larger student variances in regions with a large immigrant share.

The significance levels reported in Table 4 (and Table 5 below) are based on the assumption of a normal distribution of the standard errors. As this assumption can be questioned we have also used a bootstrap approach to test if there are significant differences across regions in the between-school variance share of total variance when individual socio-economic background and immigrant background is controlled for (model 3). Our analysis shows that the between-school variance share in the VMS-high region is significantly larger than in the VMS-low (5\% level), VMS-medium (1\% level), and VMS-medium (5\% level) regions. The same is true for the VMS-low and VMS-medium regions when considered jointly in relation to the VMS-medium high and VMS-high regions taken as a single group (significance level is $1 \%$ ). Details on the bootstrap approach are available from the authors upon request.

In addition to the ESCS variable and the immigrant status variable we introduced a gender variable. However, the introduction of the gender variable did not change the results and did not have a significant effect.

The next step is to analyse whether school-level effects are linked to the average socio-economic status of the children. The issue at stake is if a concentration of children from socially 
disadvantaged backgrounds or from advantaged backgrounds has an effect on the performance of individual pupils? To do this, we introduce the school mean value of ESCS into the model. As shown in model 4 in table 5, average socio-economic status at the schools explains some of the variation in pupil performance. There is also a reduction of between-school variance in the highVMS category. This indicates that higher levels of socio-economic school segregation to some extent can explain larger performance differences across schools in regions with high shares of visible minority children. This is also in accordance with earlier studies showing the importance of SES for pupil performance (Andersson, 2004; SCB, 2007). However, even when this factor is accounted for, between-school variance is higher in regions with high or medium level shares of visible minority children.

In the next step, we use the share of foreign-born in the school neighbourhood instead of the PISA-based measure of average socio-economic status. Will the share of foreign born in the school neighbourhood explain why there is a variance between schools? As shown in model 5 in table 5, this variable does a better job of accounting for the differences in between-school variance across regions with different shares of visible minority children. When the share of foreign born in the school neighbourhood is controlled for, there is no longer any clear indication that regions with high shares of minority children are affected by higher between-school variance.

A similar negative effect of neighbourhood composition has been explored in earlier research in Sweden in multilevel models, for instance by Andersson and Subramanian (2006) on length of education, and Dryler (2001) on reduced grades and increased drop-out rates (but also the increasing odds of choosing a theoretical profile at upper secondary school). Szulkin and Jonsson 
(2007) find depressed grades among first-generation immigrants in Sweden. In a Statistics Sweden study, also controlling for individual level variables, school effects remained after controlling for both neighbourhood and school composition. The highest risk of ineligibility to upper secondary school was found among adolescents in immigrant-dense areas who attended a school with high shares of pupils of foreign background (SCB, 2007). 
Table 5. Multilevel model with pupil level ESCS, school level ESCS, share of foreign born in school neighbourhood and region ESCS mean

\begin{tabular}{|c|c|c|c|}
\hline Parameter & $\begin{array}{l}\text { Model } 4 \\
\text { Estimate (S.E.), Sign. }\end{array}$ & $\begin{array}{l}\text { Model } 5 \\
\text { Estimate (S.E.), Sign. }\end{array}$ & $\begin{array}{l}\text { Model } 6 \\
\text { Estimate (S.E.), Sign. }\end{array}$ \\
\hline \multicolumn{4}{|l|}{ Fixed effect intercepts } \\
\hline VMS-low & $2013.103(14.975) * *$ & $2043.515(16.071) * *$ & $2013.424(17.643) * *$ \\
\hline VMS-medium & $2001.974(11.788) * *$ & $2038.682(11.150) * *$ & $2024.803(12.147) * *$ \\
\hline VMS-medium/high & $2007.185(18.947) * *$ & $2038.372(18.411) * *$ & $2023.108(21.845) * *$ \\
\hline VMS-high & $1981.914(12.748) * *$ & $2045.330(11.841) * *$ & $1961.124(13.718) * *$ \\
\hline \multicolumn{4}{|l|}{ Level 1 (Pupil specific) } \\
\hline \multicolumn{4}{|l|}{ Fixed variance components } \\
\hline ESCS & $140.350(5.515) * *$ & $146.257(5.344) * *$ & $140.699(5.516) * *$ \\
\hline Immigrant status & $-150.898(14.963) * *$ & $-133.966(15.497)^{* *}$ & $-146.247(14.956)^{* *}$ \\
\hline \multicolumn{4}{|l|}{ Level 2 (School specific) } \\
\hline \multicolumn{4}{|l|}{ Fixed variance components } \\
\hline Mean ESCS value & $95.980(20.451) * *$ & & \\
\hline ESCS mean VMS-low & & & $92.352(60.970)$ \\
\hline ESCS mean VMS-medium & & & $-20.650(36.811)$ \\
\hline $\begin{array}{l}\text { ESCS mean VMS } \\
\text { medium/high }\end{array}$ & & & $1.138(69.432)$ \\
\hline ESCS mean VMS-high & & & $152.677(25.568)^{* *}$ \\
\hline $\begin{array}{l}\text { Share foreign born in } \\
\text { school neighbourhood }\end{array}$ & & $-316.144(58.398) * *$ & \\
\hline Random variance components & $\begin{array}{l}\text { Estimate, Sign.(S.E.) } \\
\% \text { of variation }\end{array}$ & $\begin{array}{l}\text { Estimate, Sign.(S.E.) } \\
\% \text { of variation }\end{array}$ & $\begin{array}{l}\text { Estimate, Sign.(S.E.) } \\
\% \text { of variation }\end{array}$ \\
\hline $\begin{array}{l}\text { VMS-low } \\
\text { (Within school) }\end{array}$ & $\begin{array}{l}83464.83 * * \\
(4624.393) 97.36 \%\end{array}$ & $\begin{array}{l}83379.77 * * \\
(4619.93) 96.31 \%\end{array}$ & $\begin{array}{l}83439.97 * * \\
(4622.99) 97.37 \%\end{array}$ \\
\hline $\begin{array}{l}\text { VMS-low } \\
\text { (Between school) }\end{array}$ & $\begin{array}{l}2264.09 \\
(1528.302) 2.64 \%\end{array}$ & $\begin{array}{l}3196.72 * \\
(1789.92) 3.69 \%\end{array}$ & $\begin{array}{l}2254.16 \\
(1524.99) 2.63 \%\end{array}$ \\
\hline $\begin{array}{l}\text { VMS-medium } \\
\text { (Within school) }\end{array}$ & $\begin{array}{l}90177.84 * * \\
(3862.29) 98.12 \%\end{array}$ & $\begin{array}{l}90320.70 * * \\
(3868.32) 98.58 \%\end{array}$ & $\begin{array}{l}90425.76 * * \\
(3872.48) 99.46 \%\end{array}$ \\
\hline $\begin{array}{l}\text { VMS-medium } \\
\text { (Between school) }\end{array}$ & $\begin{array}{l}1729.18 \\
(1123.92) 1.88 \%\end{array}$ & $\begin{array}{l}1298.84 \\
(1029.99) 1.42 \%\end{array}$ & $\begin{array}{l}495.085 \\
(855.60) 0.54 \%\end{array}$ \\
\hline $\begin{array}{l}\text { VMS-medium/high } \\
\text { (Within school) }\end{array}$ & $\begin{array}{l}80660.70 * * \\
(4582.17) 93.65 \%\end{array}$ & $\begin{array}{l}80677.85 * * \\
(4583.25) 94.10 \%\end{array}$ & $\begin{array}{l}80465.18 * * \\
(4570.68) 94.00 \%\end{array}$ \\
\hline $\begin{array}{l}\text { VMS-medium/high } \\
\text { (Between school) }\end{array}$ & $\begin{array}{l}5472.67 * \\
(2454.11) 6.35 \%\end{array}$ & $\begin{array}{l}5055.86 * \\
(2330.37) 5.90 \%\end{array}$ & $\begin{array}{l}5133.65 * \\
(2355.68) 6.00 \%\end{array}$ \\
\hline $\begin{array}{l}\text { VMS-high } \\
\text { (Within school) }\end{array}$ & $\begin{array}{l}87126.83 * * \\
(2736.17) 94.62 \%\end{array}$ & $\begin{array}{l}87233.25 * * \\
(2739.31) 95.41 \%\end{array}$ & $\begin{array}{l}87151.59 * * \\
(2736.75) 95.10 \%\end{array}$ \\
\hline $\begin{array}{l}\text { VMS-high } \\
\text { (Between school) }\end{array}$ & $\begin{array}{l}4949.86 * * \\
(1311.15) 5.38 \%\end{array}$ & $\begin{array}{l}4195.59 * * \\
(1195.21) 4.59 \%\end{array}$ & $\begin{array}{l}4486.56 * * \\
(1241.57) 4.90 \%\end{array}$ \\
\hline$-2 * \log$ likelihood & 65001.45 (4567 cases) & 64996.45 (4567 cases) & 64985.93 (4567 cases) \\
\hline
\end{tabular}

\footnotetext{
$* \mathrm{p}<0.05, * * \mathrm{p}<0.01$.
} 
In the PISA reports it was pointed out that there are not only differences between countries with respect to between-school variance in pupil performance but also differences in the extent to which the average socio-economic status of pupils in a school influences pupil performance. Can this pattern be established also in Swedish data across regions with different shares of visible minority children? Model 6 in table 5 gives the answer. Here, the effect of average ESCS is allowed to vary across regions with different visible minority shares. The result clearly shows that average ESCS has a much stronger effect on pupil performance in the high-VMS category than in other regions. This can be seen as indicating that the effect of socio-economic segregation on educational performance gets stronger when there is a larger presence of visible minority children in the school system.

\section{Discussion}

The patterns of socio-economic and ethnic segregation we have identified in Swedish data do not contradict the idea that Schelling-type dynamic processes have been important factors in the transformation of the Swedish school system. The highest level of segregation is found in urban areas with high visible minority shares in the pupil population. We have also found that betweenschool variance in pupil performance is higher in urban areas with high or medium-high visible minority shares than in regions with low or medium shares.

To establish a non-contradiction is not the same thing however as positive proof. Therefore, it can be of interest to consider other supporting empirical evidence.

One important study here is Brännström (2004). He shows, with regard to children who went to school in Stockholm during the 1960s, that the outcome for those who grew up in a poor neighbourhood is not more likely to be worse than for those who grew up in a more affluent 
neighbourhood, when individual and family background factors are controlled for. This indicates that the strong contextual effect we find for the Stockholm area (a VMS-high region) in 2003 is a relatively recent phenomenon, meaning that it may be the result of processes of school segregation and school differentiation that were triggered by increasing shares of visible minority pupils after 1980. As showed by Eger (2009) the period between Brännström's study and ours can be described as a period of immigration. Immigration can be recognized as a factor lowering the support for universalism in the Swedish welfare regime, and increasing the support for selective welfare spending. This is a development that has added to the differences between schools, and as we see it is an ingredient in the racialization of the Swedish society.

A Schelling-type interpretation of the Swedish case is also supported if Sweden is compared to Finland. During the last few decades Finland has had a much more restrictive immigration policy than Sweden. This has resulted in low visible minority shares in the population (compare this study's VMS low to medium regions only). And, as one would expect according to the mechanism we have discussed in this paper, the Finnish school system exhibits both low levels of between-school variance and small effects of school-level socio-economic and cultural status on pupil performance (OECD, 2004).

A depressing implication of these findings is that an inflow of visible minorities can have negative effects on socio-economically disadvantaged parts of the majority population. Majority groups that manage to get their children into well-performing schools will not suffer from increasing quality differences between schools. It is instead disadvantaged families who cannot move into affluent neighbourhoods or take advantage of school choice options that will suffer when between-school variance in pupil performance increases. This may generate a well- 
founded scepticism towards liberal immigration policies, not because immigrants as such would constitute a threat but because of the awareness that disadvantaged parts of the majority population will be hurt when the middle-class turns its back on neighbourhoods and schools they consider to have too high visible-minority shares.

On a more positive note on the other hand it should not be forgotten that levels of school segregation and school differentiation in Sweden are still relatively low viewed from an international perspective. It is the direction of change that is the main problem. Our view is that processes of segregation are not beyond social control. It is still possible to enact either policies that promote further school segregation or that help roll back segregation. 


\section{References}

Ainsworth, J. W. (2002). Why does it take a Village? The Mediation of Neighborhood Effects on Educational Achievement. Social Forces 81, no. 1: 117-152.

Andersson E, 2004, "From Valley of Sadness to Hill of Happiness - The Significance of Surroundings for Socioeconomic Career" Urban Studies 41 641-659

Andersson E, Subramanian S V, 2006, "Explorations of neighborhood and educational outcomes for young Swedes" Urban Studies 43 2013-2025

Andersson R, Musterd S, Galster G, Kauppinen T M, 2007, "What Mix Matters? Exploring the Relationships between Individuals' Incomes and Different Measures of their Neighbourhood Context" Housing Studies 22637 $-660$

Bernelius V, 2006, "On the path of learning: Urban segregation and the educational outcomes of comprehensive schools in Helsinki" Helsinki Quarterly 06 22-27

Biterman D, 2006 Boendesegregation kap. 6 in Social rapport (Socialstyrelsen, Stockholm)

Boustan L P, 2010, "Was postwar suburbanization "white flight"? Evidence from the black migration " The Quarterly Journal of Economics, 125 417-443

Bråmå $\AA$, 2006, "'White flight'? The production and reproduction of immigrant concentration areas in Swedish cities, 1990-2000" Urban Studies 43 1127-1146

Bråmå Å, 2008, "Dynamics of ethnic residential segregation in Göteborg, Sweden, 1995-2000" Population, Space and Place 14 101-117

Brännström L, 2004, "Poor Places, Poor Prospects? Counterfactual Models of Neighbourhood Effects on Social Exclusion in Stockholm, Sweden" Urban Studies 41 2515-2537

Brännström L, 2008, "Making Their Mark: The Effects of Neighbourhood and Upper Secondary School on Educational Achievement" European Sociological Review jcn013

Bunar, N., 2010, The Controlled School Market and Urban Schools in Sweden, Journal of School Choice, 4, 4773.

Burgess S, McConnell B, Propper C, Wilson D, 2005 The Impact of School Choice on Sorting by Ability and Socio-economic Factors in English Secondary Education (CMPO, University of Bristol, Bristol)

Burgess S, Wilson D, Lupton R, 2005, "Parallel Lives? Ethnic Segregation in Schools and Neighbourhoods" Urban Studies 42 1027-1056

Card D, Mas A, Rothstein J, 2008, "Tipping and the dynamics of segregation" Quarterly Journal of Economics $123177-218$

Clark W A V, 1991, "Residential preferences and neighborhood racial segregation - a test of the Schelling segregation model" Demography 28 1-19 
Clotfelter C T, 1976, "School Desegregation, "Tipping," and Private School Enrollment" The Journal of Human Resources 11 28-50

Dryler H, 2001, "Etnisk segregation i skolan - effekter på ungdomars betyg och övergång till gymnasieskolan", in Välfärdens finansiering och fördelning (Socialdepartementet, Forskarantologi från Kommittén Välfärdsbokslut, Stockholm) pp 319-355

Dumay X, Dupriez V, 2008, "Does the school composition effect matter? Evidence from Belgian data" British Journal of Educational Studies 56 440-477

Eger, M. A. (2009) Even in Sweden: The Effect of Immigration on Support for Welfare State Spending. Eur Sociol Rev, jcp017.

Fekjaer S N, Birkelund G E, 2007, "Does the Ethnic Composition of Upper Secondary Schools Influence Educational Achievement and Attainment? A Multilevel Analysis of the Norwegian Case" Eur Sociol Rev 23 309-323

Friedrichs J, Galster G, Musterd S, 2003, "Neighbourhood Effects on Social Opportunities: The European and American Research and Policy Context" Housing Studies 18 797-806

Friskolornas riksförbund, 2009, "(Swedish Association of Voucher Schools)

http://www.friskola.se/Om_oss_In_English_DXNI-38495_.aspx"

Galster G C, Quercia R G, Cortes A, 2000, "Identifying neighborhood thresholds: An empirical exploration" Housing Policy Debate 11 701-732

Galster G, 2002, "Trans-Atlantic Perspectives on Opportunity, Deprivation and the Housing nexus" Housing Studies 17 5-10

Harker, R, Tymms, P. 2004, The Effects of Student Composition on School Outcomes. School Effectiveness and School Improvement, 15 177-200.

Hedberg C, 2009, "Entrance, Exit and Exclusion: Labour Market Flows of Foreign-born Adults in Swedish 'Divided Cities"' Urban Stud 46 2423-2446

Ihlanfeldt K, Scafidi B, 2004, "Whites' neighbourhood racial preferences and neighbourhood racial composition in the United States: Evidence from the multi-city study of urban inequality" Housing Studies 19 325-359

Karsten S, Ledoux G, Roeleveld J, Felix C, Elshof D, 2003, "School Choice and Ethnic Segregation " Educational Policy 17 452-477

Kauppinen T, 2008, "Schools as Mediators of Neighbourhood Effects on Choice Between Vocational and Academic Tracks of Secondary Education in Helsinki" European Sociological Review 24 379-391

Ledwith V, Clark W A V, 2007, "The effect of the residential mosaic and "White flight" on public school composition: Evidence from Los Angeles County" Urban Geography 28 160-180

Li M, 2009, "Is there "white flight" into private schools? New evidence from High School and Beyond" Economics of Education Review 28 382-392

Murdie R A, Borgegard L-E, 1998, "Immigration, Spatial Segregation and Housing Segmentation of Immigrants in Metropolitan Stockholm, 1960-95" Urban Stud 35 1869-1888

Noreisch K, 2007, "School catchment area evasion: the case of Berlin" Journal of Education Policy 22 69-90 
OECD, 2003, "The PISA International Database"

OECD, 2004 Learning for tomorrow's world: first results from PISA 2003 (Organisation for Economic Cooperation and Development, Paris)

OECD, 2006 Where Immigrant Students Succeed - A Comparative Review of Performance and Engagement in PISA 2003

Oríaa A, Cardinib A, Balla S, Stamoua E, Kolokithaa M, Vertigana S, Flores-Morenoa C, 2007, "Urban education, the middle classes and their dilemmas of school choice" Journal of Education Policy 22 91-105

Östh J, Andersson E, Malmberg B, 2009 Increasing between-school variation in the performance of Swedish students: An effect of school choice? AAG conference, Las Vegas.

PLACE Population, Chorology and Employment Database, 2009, Department of Social and Economic geography, Uppsala University, from statistics Sweden.

Rangvid B S, 2007, "Living and Learning Separately? Ethnic Segregation of School Children in Copenhagen" Urban Studies 44 1329-1354

Saporito S, Lareau A, 1999, "School Selection as a Process: The Multiple Dimensions of Race in Framing Educational Choice" Social Problems 46 418-439

SCB, 2007 Barn, boendesegregation och skolresultat (Children, segregated housing and school results) Statistics Sweden, Stockholm.

Schelling T C, 1978 Micromotives and macrobehavior (Norton, New York)

Sykes B, Kuyper H, 2009, "Neighbourhood effects on youth educational achievement in the Netherlands: Can effects be identified and do they vary by student background characteristics?" Environment and Planning $A \mathbf{4 1}$ $2417-2436$

Szulkin R, Jonsson J O, 2007, "Ethnic segregation and educational outcomes in Swedish comprehensive schools" Working Paper

van Ham M, Feijten P, 2008, "Who wants to leave the neighbourhood? The effect of being different from the neighbourhood population on wishes to move" Environment and Planning A 40 1151-1170

Vogel J, 1992, "Urban Segregation in Sweden Housing Policy, Housing Markets, and the Spacial Distribution of Households in Metropolitan Areas" Social Indicators Research 27 139-155

White M J, 1986, "Segregation and Diversity Measures in Population Distribution" Population Index 52 198-221

Wilson W J, 1987 The Truly Disadvantaged: The Inner City, the Underclass, and Public Policy (The University of Chicago Press, Chicago and London) 